\title{
Implicit change leadership schemas, perceived effective change management, and teachers' commitment to change in secondary schools in the Philippines
}

\author{
Joyce M. Guerrero ${ }^{1}$ (1) $\cdot$ Mendiola Teng-Calleja ${ }^{2}\left(\mathbb{D} \cdot\right.$ Ma. Regina M. Hechanova ${ }^{2}$
}

Received: 23 April 2017 / Revised: 17 May 2018 / Accepted: 22 May 2018 / Published online: 26 May 2018

(c) Education Research Institute, Seoul National University, Seoul, Korea 2018

\begin{abstract}
Implicit change leadership theory (ICLT) highlights the importance of determining congruence between the ideal and actual change leadership schemas of employees in successful change management. This paper utilized ICLT in exploring effective change leadership and management in secondary schools and examined how these influence teachers' commitment to change. Data were gathered from 707 secondary school teachers from both private and public high schools in the Philippines. Findings indicated that (1) teachers seem to have a more holistic and integrative view of change leadership schemas than employees of business organizations, (2) teachers' change leadership schemas significantly predicts perceived effectiveness of change management, and teachers' affective commitment to change, and (3) perceived effectiveness of change management significantly mediates the effect of change leadership schemas on teachers' affective commitment to change. This study expanded the applicability of ICLT in basic education settings and contributes to the understanding of effective change leadership and change management in schools. Implications on practice and further recommendations for school leaders are also discussed.
\end{abstract}

Keywords Change leadership $\cdot$ Change management $\cdot$ Commitment to change $\cdot$ Academic institutions $\cdot$ Teachers . Philippines

\section{Introduction}

Change is the only thing constant. We live in a world where development means leaving old paradigms and embracing new perspectives. Similarly, academic institutions are called to adapt to an increasingly competitive and complex environment. A relevant example would be the $\mathrm{K}$ to 12 education system, that has now become the standard for basic education globally. This has put pressure on countries that had previously not utilized it to embrace the $\mathrm{K}$ to 12 system, and this had required major changes. A study endorsed by the Asian Development Bank (Sarvi et al. 2015) looked at the effect of transition to the $\mathrm{K}$ to 12 in five different areasMongolia, Ontario (Canada), the Philippines, Poland, and

Joyce M. Guerrero

joyce.guerrero@obf.ateneo.edu

1 Ateneo de Manila University, Quezon City, Philippines

2 Psychology Department, Ateneo Center for Organization Research and Development, Ateneo de Manila University, 107 G/F Frank Lynch Building, Quezon City, Philippines
Turkey. These countries were found to encounter varied adjustments depending on their political, fiscal, socioeconomic, and educational contexts. Basic education schools experienced restructuring, not just in curriculum, but also in financial and human resources (Sarvi et al. 2015).

The commitment of organization members is critical for any change effort to succeed, and the capacity to engender commitment to change is an important characteristic of organization leaders (Ashkenas et al. 2013). A study shows that in basic education units, effective change efforts in schools are the ones initiated by school principals (Parco-Tropicales and de Guzman 2014). They examined the influence of principals in organizational change using various theories-transformational, visionary, charismatic, and ethical, among others (Parco-Tropicales and de Guzman 2014). However, in recent years, an emerging perspective of leadership focuses on followers. One of the most recently developed perspective is the implicit leadership theory (ILT). It presupposes that because leadership is dyadic in nature, the effectiveness of leaders depends, to some extent, on whether they meet the expectation of their followers or not. The ILT suggests that followers have schemas of ideal leaders and evaluates the effectiveness 
of their leaders based on these expectations (Epitropaki and Martin 2005). Building on ILT, Magsaysay and Hechanova (2017) proposed that leadership requirements are dependent on context. Thus, leadership characteristics needed during times of change may be different from periods of stability. They proposed the implicit change leadership theory (ICLT) that focuses on the difference between the subordinates' ideal and observed leader behaviors and traits in the context of organizational change.

This study expands the literature on leading change in the school setting by looking at the role of leadership from the perspective of the ICLT. This theory, which was anchored on ILT, assumes that people create schemas of their ideal change leader, and compare it to their observations of actual leader behaviors during organizational change. Moreover, it found support for the relationship of the congruence between the ideal characteristics and actual observations of change leaders and perception of change management effectiveness (Magsaysay and Hechanova 2017). The viability of ICLT in explaining perceived effectiveness of change management has been established in business settings. However, this paper expands the understanding of ICLT and organizational change in two ways. First, it looks at the extent to which congruence with change leadership schemas predict commitment to change and perceptions of effective change management in the context of the academe. Second, it explores the extent to which perceptions of change management mediates the relationship between change leader schema congruence and commitment to change.

This study was conducted in schools in the Philippines that shifted from a 10 -year curriculum to a $\mathrm{K}$ to 12 system. The Philippine K to 12 program aims to contextualize learning for core and elective subjects, adapt dual vocational education, and include cognitive and non-cognitive competencies in the curriculum (Sarvi et al. 2015). As part of the shift, schools adjusted grade levels, created new curricula, modified the organizational structure, among other changes (How DepEd Prepares for the K to 12 Program 2015). Given the magnitude of the transformation, getting the buy-in of teachers and ensuring effective change management are critical to the success of the $\mathrm{K}-12$ program. Because teachers are the primary implementers of a curriculum, their relationships with principals greatly affect how they perceive and commit to the changes (Brooks and Sutherland 2014). This emphasizes the need to explore teachers' experience of change and change leadership in academic institutions.

\section{Review of literature}

\section{Implicit change leadership theory}

The implicit leadership theory (ILT) presupposes that people have expectations of their leaders and evaluates the effectiveness of their leaders based on these expectations (Epitropaki and Martin 2005). Magsaysay and Hechanova (2017) expanded ILT in the context of change and proposed the implicit change leadership theory. They suggested that leadership contexts are dynamic, and thus, the requirements of leadership will depend on what they are expected to do. ICLT assumes that people have their own mental model of a change leader and they will use this as basis in assessing effective leadership during organizational change. A change leader is perceived to be more effective if there is congruence between schemas of ideal change leaders and actual leader behaviors (Magsaysay and Hechanova 2017).

The ICLT dimensions as reported by Magsaysay and Hechanova (2017) consists of five change leadership schemas (behaviors and traits expected of an ideal change leader) found to be relevant to subordinates during change. These are strategic and technical, execution, social, character, and resilience (Magsaysay and Hechanova 2017). The strategic and technical dimension describes a change leader who is analytical, knowledgeable, proactive, open-minded, strategic visionary, and innovative and creative. The execution dimension suggests a change leader needs to be decisive, conscientious and not lazy, inspiring, persuasive, strong-willed, not a micro-manager, effective coach/mentor, action- and results-oriented, and drives execution and accountability. The social dimension suggests that change leaders should be supportive, not bossy, empathic, participatory, approachable, not distrustful, people-oriented, and an effective communicator. The character dimension describes change leaders as being honest, leading by example, and being credible and respected. The last dimension, resilience, suggests that change leaders should be positive, optimistic, adaptable/flexible, composed under pressure, and not emotional or sensitive. Figure 1 summarizes the five schemas and the specific characteristics for each.

As previously mentioned, the change leadership schemas were found to predict effective change management in business organizations (Magsaysay and Hechanova 2017). However, there is a lack of research on the applicability of ICLT among academic institutions. Hence, this study examines the relationship between these two variables in the school setting.

\section{Leadership and change management in schools}

ILT researches in schools have focused on leadership qualities of teachers from the students' perspective (e.g., Yermack and Forsyth 2016). However, numerous studies have recommended using ILT in examining the dynamics between the principal and teachers to further understand leadership in schools (Kin et al. 2015; Parco-Tropicales and De Guzman 2014; Taş 2009). 
Fig. 1 Description of schemas of change leaders adapted from the study of Magsaysay and Hechanova (2017)

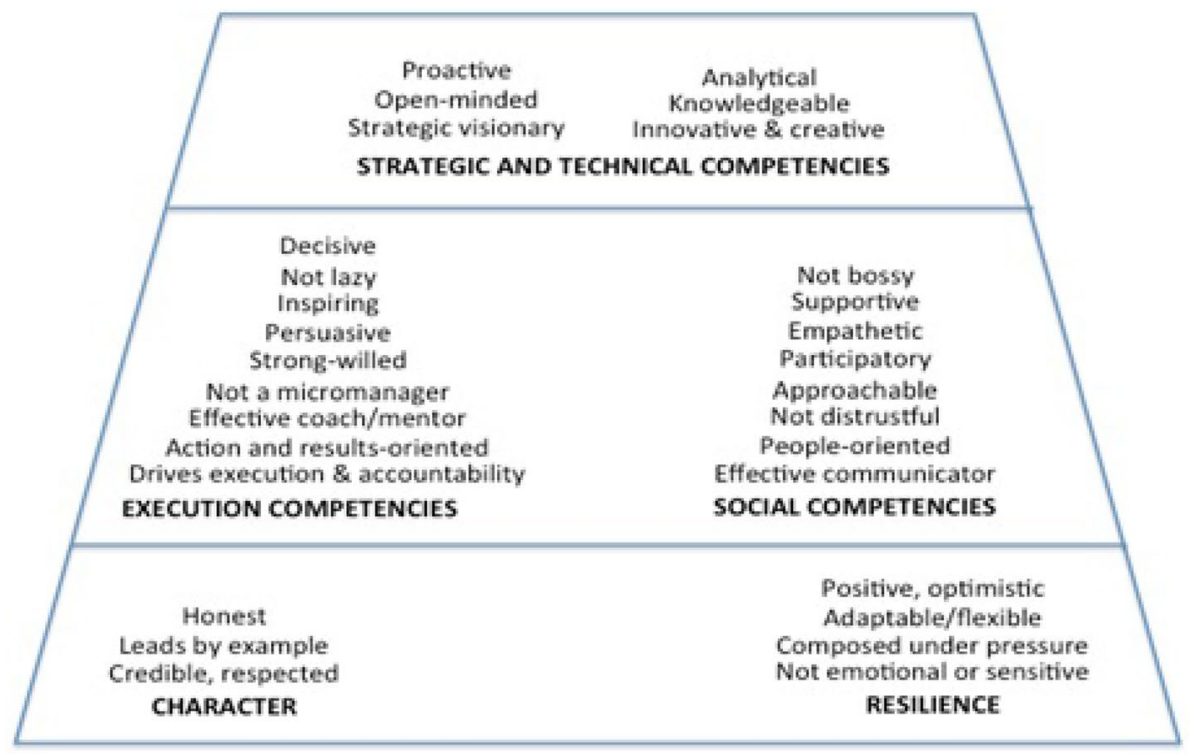

As leaders of schools, principals are typically the change agents in the organization (Hechanova and Cementina-Olpoc 2013; Parco-Tropicales and de Guzman 2014). Studies have suggested that these leaders should initiate change, maintain support network, and practice ethical and proactive leadership in times of change (Melville et al. 2012). However, a study by Taş (2009) reported that teachers do not always see their principals taking risks to carry out the change that they are promoting.

Magsaysay and Hechanova (2017) also explored factors that contribute to the successful management of change. Their study of effectiveness of change management yielded ten change management processes. The first of which is planning the strategy and process of change. Another factor is communicating change-making sure that people understand the reason for change and what changes will be implemented. Training also surfaced as an important element in change management to ensure that people have the capabilities to implement the change. Preparation and readiness was also seen as important in effectively managing change. This entails ensuring that employees are ready and confident about their ability to implement the change. Having an organization culture supportive of change also helps ensure success. Employees also expect leaders to be visibly and tangibly supporting the change. Employee roles and responsibilities and deliverables during the change need to be clear and monitored. Furthermore, it is important for organizations to harness technologies that enable people to work better during the change. Lastly, the organization's structure and workflow should support the change initiative.

Magsaysay and Hechanova's (2017) study on change management practices was conducted among business organizations. However, a study comparing business and academic organizations reported a significant difference in perceptions of effective change management in these two types of organizations (Hechanova and Cementina-Olpoc 2013). It reports that in academic organizations, leadership support is a significant factor in managing change compared to business organizations. It is important for employees of academic institutions that their leaders support the change, be transparent about it, and be sensitive to how it is being received in the organization. Using transformational leadership theory, they report that respondents from the academe expressed greater value for having leaders who "model the way" and "encourage the heart" compared to their counterparts in business. They suggest that this may be because leadership is collegial and fluid in schools. This is in contrast with business organizations that value position and hierarchy, and where leaders can impose change (Hechanova and Cementina-Olpoc 2013).

Sosik et al. (2005) further emphasized the difference between the academe and business organizations. They found that teachers are more motivated by intrinsic, rather than extrinsic, rewards. In their study, employees of hightech firms valued high salaries, stock incentives, and bonuses as rewards for their efforts. On the other hand, given the altruistic nature of the profession, teachers view pride, selfesteem, and the desire to help others succeed, as rewards in themselves. Based on the mentoring framework of Colley, Hodskinson, and Malcolm (as cited in Sosik et al. 2005), the spirit of friendship, collaboration, collegiality, and shared values are intrinsic rewards in the academe. This further highlights the role of leaders and their relationships with teachers as driving forces for change.

The ICLT was built by looking at business organizations. Given the literature highlighting distinctions between business and academe, this study explored the applicability of the change management processes in business organizations 
to the school setting. Furthermore, it determined whether the schemas of change leaders also predict teacher's perceptions of how effective change was managed in the organization.

\section{Change leadership and change management as predictors of teachers' commitment to change}

Research has proven that employees' acceptance and support for change are needed for its successful implementation (Fedor et al. 2006). Thus, it is valuable to look at teachers' commitment to change in school settings. Commitment to change is defined by Herscovitch and Meyer (2002) as attaching one's self with the actions necessary for the change to be successful. It is composed of three dimensions. The affective dimension refers to the desire for change based on the belief in its inherent benefits or positive effects. Another is the continuance dimension or the need for change. This refers to the costs associated with the failure to support the change. Lastly, the normative dimension pertains to a sense of obligation to provide support for the change.

Literature describe multiple predictors of commitment to change. Transformational leadership has been identified as one of the predictors of commitment to change in various studies. A longitudinal study by Seo et al. (2012) looked at managers' transformational leadership influencing employees' affective and normative commitment to change. They found that transformational leadership behaviors demonstrated by managers positively predict employees' affective and normative commitment to change. This means that employees who perceive their leaders as transformational are more likely to commit to change.

Unlike transformational leadership theory, ICLT is a follower-centric approach. It considers the difference between the subordinates perceived ideal and actual leadership behaviors, and thus, brings to light something that has not been considered in other leadership theories. This is a gap that the current study aims to bridge.

Change management has a strong association with commitment to change. Hechanova and Teng-Calleja (2011) looked at multiple predictors of commitment to change of employees from various sectors, including the academe, and found that change management has the highest contribution to commitment to change compared to culture of innovation and quality of relationship. Employees who perceive that change is managed effectively are more likely to commit to the change.

The findings demonstrate the significant relationship between leadership, change management, and employees' commitment to change in different organizations, including academic institutions. Similarly, this study proposes that leadership (i.e., schemas of change leaders) and perceived effective change management will predict teachers' commitment to change.

\section{Mediating role of change management}

Change management has also been found to mediate the relationship between transformational leadership and commitment to change. Hechanova and Cementina-Olpoc (2013) examined differences between the academe and business organizations in aspects of transformational leadership, change management, and commitment to change. They found that in the academe, perceptions of effectiveness of change management mediates the relationship between transformational leadership and teachers' commitment to change. As such, this study seeks to examine the mediating role of change management between ICLT and the commitment to change of teachers (Fig. 2).

\section{Research questions}

Although there is much evidence for the importance of leadership and change management on commitment to change, there is a dearth of studies on follower schemas, especially in the academe. As such, this study aims to bridge that gap by exploring the mediating effect of perceived effectiveness of change management between change leadership schemas and commitment to change in schools. It examines how change leader schemas shape perceptions of change management effectiveness in an academic context, and predict teachers' commitment to change. This study specifically sought answers to the following research questions:
Fig. 2 The hypothesized relationships among change leadership schemas, perceived effective change management, and commitment to change

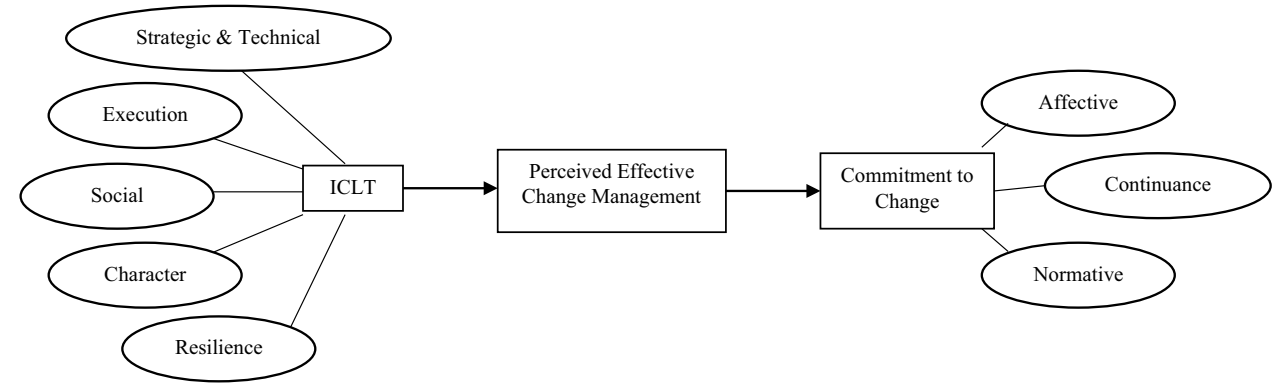


(1) What are the schemas of teachers on the characteristics of ideal change leaders in the school setting?

(2) Does congruence of ideal change leadership schemas with actual leadership behaviors, predict perceived effectiveness of change management?

(3) Does congruence of ideal change leadership schemas with actual leadership behaviors, predict teacher's commitment to change?

(4) Does perceived effectiveness of change management mediate the relationship between congruence of ideal change leadership schemas with actual leadership behaviors and teacher's commitment to change?

The following hypotheses guided the study:

Hypothesis 1 The congruence of ideal change leadership schemas with actual leadership behaviors predict perceived effectiveness of change management.

Hypothesis 2 The congruence of ideal change leadership schemas with actual leadership behaviors predict teachers' commitment to change.

Hypothesis 3 The effectiveness of change management mediates the influence of implicit leadership schemas on teachers' commitment to change.

\section{Method}

This study used a quantitative approach in exploring secondary school teachers' perception of change leadership and change management in basic education units, and whether these predict commitment to change.

\section{Sampling and data collection}

Seven hundred seven (707) high school teachers from 14 public and 16 private schools in the Philippines participated in the research. Respondents were chosen through purposive sampling among high school teachers. The number of participants from each school was controlled to be 40 or less, so as not to skew the data to one school. Thirty-eight responses were removed because these have more than $25 \%$ missing data. After data cleaning, the number of valid responses totaled to 669.

Teachers responded through either paper and pen or online survey. Each survey included an informed consent stating that respondents were willing to participate in the study. Those who preferred online copies received survey links through their indicated emails, while the rest received printed copies that were distributed and collected in a sealed envelope through the schools' principals, guidance counselors, and subject coordinators.

Three hundred and two (302 or $45 \%$ ) work in private schools, while 367 (55\%) work in public schools. An independent samples $t$ test was conducted to determine whether there are differences in the scores of participants from private schools and public schools. Results indicated no significant differences in the scores of private school teachers $(M=4.52, \mathrm{SD}=.53)$ and public school teachers $(M=4.47$, $\mathrm{SD}=.51 ; t(669)=1.416 ; p=.16)$. The mean age is 37 years old, with majority or $399(60 \%)$ being female teachers. Two hundred five (31\%) listed experiencing changes in programs, followed by changes in policies with 140 respondents $(21 \%)$; $115(17 \%)$ indicated renovations, $114(17 \%)$ felt changes in workload, $108(16 \%)$ in systems, and $105(16 \%)$ in structure; $94(14 \%)$ responded with changes in strategy; $78(12 \%)$ in automation, $69(10 \%)$ in expansion, and $51(8 \%)$ in vision; $25(4 \%)$ indicated mergers and acquisitions, 12 (2\%) identified transfer, and another 12 (2\%) for other types of changes. This study allowed respondents to choose one or more type/s of change they have experienced in the organization.

\section{Research instruments}

The questionnaire used by Magsaysay and Hechanova (2017) to measure schemas of leaders and perceived effectiveness of change management processes was adopted in this study. Commitment to change was measured using Herscovitch and Meyer's (2002) Commitment to Change scale. The questionnaires are described in the following paragraphs.

\section{Change leadership schema}

Respondents described characteristics of their ideal change leader using the 30 change leader schemas from Magsaysay and Hechanova's study (2017). After which, participants were asked to identify the change leader in a specific change initiative of their school and to report observations of this leader's behavior using the same 30 change leader schemas. Each item was rated on a scale of 1 (not at all characteristic) to 6 (extremely characteristic). The discrepancy between the ideal and actual change leader was calculated using their absolute difference. Reliability analysis of the ICLT dimensions of the current study yielded acceptable Cronbach's alpha-strategic and technical at .83 , execution at .85 , social at .87 , character at .72 , and resilience at .75 . They were also within the same range of reliability scores reported by Magsaysay and Hechanova (2017)—strategic and technical at .78, execution at .78, social at .86, character at .75 , and resilience at .74 . The reliability of the whole implicit change leadership construct in this study was Cronbach's alpha of .96 . 


\section{Perceived effectiveness of change management}

The scale used to measure this variable was also adopted from the study of Magsaysay and Hechanova (2017). The ten change management processes were measured using ten items. Sample statements include "The implementation of the change was carefully planned," "People were prepared by the organization before the change was implemented," and "The organization was able to guide employees to work towards a common goal." Each statement was measured using a 6-item scale, with the least score meaning a response of $n o, n o, n o$ and the highest score meaning a response of yes, yes, yes, describing to which extent the item applies to their experience of change. Cronbach's alpha was .97 , which is comparable to the reliability reported by Magsaysay and Hechanova (2017) $(\alpha=.94)$.

\section{Teachers' commitment to change}

Herscovitch and Meyer (2002) defined commitment to change as "a (mind-set) that binds an individual to a course of action deemed necessary for the successful implementation of a change initiative" (p. 475). It has three components namely, a desire (affective), a need (continuance), and an obligation (normative) for change. The scale on commitment to change has 18 items pertaining to the three dimensions, each having six items. The statements were rated on a scale of 1 (strongly disagree) to 6 (strongly agree). Scores for the three dimensions were calculated by getting the mean score of the items categorized under each one. The affective component (e.g., "This change serves an important purpose.") yielded a Cronbach's alpha of .77, and the continuance component (e.g., "I have no choice but to go along with this change.") an alpha of .78. Although the alpha coefficient of the affective dimension was much higher at .92 and the continuance at .71, the current study's results are still acceptable. However, the normative component (e.g., "It would be irresponsible for me to resist this change.") yielded an unacceptable Cronbach's alpha of .44 compared to Herscovitch and Meyer's (2002) alpha coefficient of .78. No improvements could be made and such, this dimension of commitment to change was no longer included in succeeding analyses of data.

\section{Data analysis}

Data were analyzed using factor analysis, descriptive statistics, and correlations. IBM SPSS 20. EQS 6.3 for Windows was utilized for initial model fit using Structural Equation Modeling, and Path analysis. For factor analysis, three statistical measures were used to test the factorability of the data as recommended by Tabachnick and Fidell (2007). These were the inter-correlation among items (majority of the correlation coefficients must be .30 and above), Bartlett's test of sphericity ( $p$ value must be $<.05$ ), and the Kaiser-Meyer-Olkin (KMO) measure of sampling adequacy (ideally greater than .50 to signify a good sample size). For Path analysis, model fit is deemed acceptable if the Chisquare is non-significant, the Normed Fit Index (NFI) and the Comparative Fit Index's (CFI) values are greater than .90, and the Root Mean Square Error of Approximation's (RMSEA) value is .08 and below (Hu and Bentler 1999).

\section{Results}

\section{Teachers' schemas of ideal change leaders}

Using principal component, an exploratory factor analysis (EFA) of the 30 ICLT items was conducted to confirm if the five factors found in business organizations were present in secondary schools. The correlation matrix showed that majority of the items have correlation coefficients of .30 or more, signifying the appropriateness of using factor analysis. The Bartlett's test of sphericity was significant at $p=.00$ while the KMO was at .97 , signifying a good sample size. As seen in Table 1, EFA produced a 3-factor model with half of the negatively worded items double loading (with very close item factor loading) in either Factors 1 or 2. Factor 3 did not have enough item loading to be a separate group, and items here double-loaded in Factor 1.

Confirmatory factor analyses (CFA) were conducted (suppressed values of $<.3$ ) with five predetermined factors because of the original model from Magsaysay and Hechanova's (2017) study, and two factors because of the results of EFA. Both did not yield good results, with the latter yielding very close factor loading of five of the eight negatively stated items. Then, a one-factor structure analysis was conducted and yielded a more sensible result with all items having factor loadings of .33 to .87 . Thus, a unidimensional factor structure of ICLT was used in the succeeding statistical analyses. Table 2 shows the results of the CFA with the unidimensional factor structure.

\section{Descriptive statistics and correlations}

Although the implicit change leadership schemas of teachers were not categorized into dimensions, results are still indicative of characteristics and behaviors that were perceived to be ideal during change in schools. Table 3 presents the mean scores of items in the survey, from highest to lowest of their ideal change leader characteristics. It answers the first research question of this study.

Results show that the top characteristic of teachers' ideal change leader is having initiative and not being lazy when it comes to change. This is followed by behaviors of not being 
Table 1 Results of exploratory factor analysis of ICLT items in secondary schools

\begin{tabular}{|c|c|c|c|}
\hline \multirow[t]{2}{*}{ Item } & \multicolumn{3}{|c|}{ Factor loading } \\
\hline & 1 & 2 & 3 \\
\hline Is lazy and lacks initiative $(r)$ & .71 & & \\
\hline Is arrogant $(r)$ & .78 & & \\
\hline Is honest, credible, and respected & .82 & & \\
\hline Inspires and motivates team members to perform at their best & .73 & & \\
\hline Leads by example and walks the talk regarding the change & .33 & & .71 \\
\hline Consults team members and allows them to participate & .70 & & \\
\hline Is an effective coach and mentor & .74 & & \\
\hline Maintains a positive outlook throughout the change implementation & .38 & & .65 \\
\hline Is innovative and creative & .71 & & \\
\hline Is firm in resolving problems and making decisions & .80 & & \\
\hline Clearly communicates plans as well as his/her expectations & .79 & & \\
\hline Shows intelligence and competence to drive the change & .81 & & \\
\hline Is persuasive; can convince people of the need for change & .82 & & \\
\hline Is open-minded about the change & .87 & & \\
\hline Shows trust in people & .85 & & \\
\hline Remains composed under pressure & .76 & & \\
\hline Cares for team members and shows consideration & .51 & & \\
\hline Shows empathy & .76 & & \\
\hline Is rational and analytical & .81 & & \\
\hline Adapts to new ways readily and quickly & .75 & & \\
\hline Drives execution and accountability & .81 & & \\
\hline Is approachable and always available & .77 & & \\
\hline Supports team members during the change & .84 & & \\
\hline Is proactive in anticipating issues and problems & .49 & .45 & \\
\hline Is bossy and authoritarian $(r)$ & .49 & .61 & \\
\hline Is too emotional or quickly changes moods $(r)$ & .46 & .36 & \\
\hline Is disorganized and lacks focus $(r)$ & .69 & & \\
\hline Lacks long-term thinking $(r)$ & .52 & .57 & \\
\hline Is passive and has no political will $(r)$ & .46 & .53 & \\
\hline Micromanages people $(r)$ & .74 & & \\
\hline
\end{tabular}

arrogant, but rather honest, credible and respected. School leaders are also expected to inspire and motivate members to perform at their best, and lead by example regarding the changes being implemented in the organization. These are closely followed by consultation with team members, coaching and mentoring, as well as maintaining a positive disposition. These top responses indicate that teachers value their leaders' disposition and attitude towards change, more than the technical skills in implementing them.

Mean scores and standard deviations of the remaining variables were also computed in the study, as seen Table 4. It includes the ICLT discrepancy (ICLT), perception of change management effectiveness (perceived $\mathrm{CM}$ ), and the affective (Affective $\mathrm{CC}$ ), and continuance (Continuance $\mathrm{CC}$ ) dimensions of commitment to change.

Descriptive results show that there is little difference between the teachers' ideal change leaders and their observations of actual change leaders as seen in the mean scores
( $M=5.05 ; M=4.65$, respectively). As such, the discrepancy yielded a low mean of 41 .

Results show relatively high scores for change management $(M=4.26)$ and affective commitment $(M=4.72)$. However, scores for continuance commitment were moderately low $(M=3.30)$.

Results in Table 4 also show that all correlations between variables were significant. ICLT was found to have a negative correlation with perceived effective change management, and affective dimension of commitment to change. This implies that when actual leaders were perceived to behave in accordance with their ideal change leaders, then respondents perceive change management to be effective. Inversely, when there is a big discrepancy between ideal and actual perception of change leadership, then teachers perceive change as ineffectively managed.

As for the dimensions of commitment to change, affective commitment was positively correlated with perceived 
Table 2 Results of one-factor confirmatory factor analysis of ICLT items in secondary schools

\begin{tabular}{|c|c|}
\hline Item & Factor loading \\
\hline Is lazy and lacks initiative $(r)$ & .71 \\
\hline Is arrogant $(r)$ & .78 \\
\hline Is honest, credible, and respected & .82 \\
\hline Inspires and motivates team members to perform at their best & .73 \\
\hline Leads by example and walks the talk regarding the change & .33 \\
\hline Consults team members and allows them to participate & .70 \\
\hline Is an effective coach and mentor & .74 \\
\hline Maintains a positive outlook throughout the change implementation & .38 \\
\hline Is innovative and creative & .71 \\
\hline Is firm in resolving problems and making decisions & .80 \\
\hline Clearly communicates plans as well as his/her expectations & .79 \\
\hline Shows intelligence and competence to drive the change & .81 \\
\hline Is persuasive; can convince people of the need for change & .82 \\
\hline Is open-minded about the change & .87 \\
\hline Shows trust in people & .85 \\
\hline Remains composed under pressure & .76 \\
\hline Cares for team members and shows consideration & .51 \\
\hline Shows empathy & .76 \\
\hline Is rational and analytical & .81 \\
\hline Adapts to new ways readily and quickly & .75 \\
\hline Drives execution and accountability & .81 \\
\hline Is approachable and always available & .77 \\
\hline Supports team members during the change & .84 \\
\hline Is proactive in anticipating issues and problems & .49 \\
\hline Is bossy and authoritarian $(r)$ & .49 \\
\hline Is too emotional or quickly changes moods $(r)$ & .46 \\
\hline Is disorganized and lacks focus $(r)$ & 69 \\
\hline Lacks long-term thinking $(r)$ & .52 \\
\hline Is passive and has no political will $(r)$ & .46 \\
\hline Micromanages people $(r)$ & .74 \\
\hline
\end{tabular}

effective change management. This means that the more teachers perceive that change is managed effectively, the more likely they are to feel committed to the change. On the other hand, continuance commitment to change was inversely correlated with perceived effective change management, which implies the opposite effect.

\section{Model validation}

Figure 3 shows the relationships between the factors of ICLT, change management, and dimensions of commitment to change. The variables were tested using path analysis with Satorra-Bentler Chi-square $=108.46, p=.00, d f=3$, but did not pass the robust goodness of fit. Relative fit indices fell short, with a CFI of .63 and NFI of .62. The adjusted fit index also did not meet the requirement, with the RMSEA at 23 .

A second model was proposed based on the recommendation of the Wald's test and the findings from previous literature. The emerging model focused on perceived effective change management mediating the influence of ICLT on affective commitment to change. Stronger correlations (as seen in Table 4) and literature review highlight the value of affective, rather than continuance dimension in measuring teachers' commitment to change. For example, Sosik et al. (2005) emphasized that teachers are motivated by their desire to help students succeed, and this intrinsic motivation may be harnessed when managing change. Similarly, the study conducted by Hechanova and TengCalleja (2011) among Filipino employees showed how leadership and perceived effective change management predict affective commitment to change.

The emerging model in Fig. 4 had a Satorra-Bentler Chi-square $=.02, p=.89, d f=1$. Relative fit indexes were CFI of $1.00 \mathrm{NFI}$ of 1.00. Adjusted fit indices reflected RMSEA of .00. All values represent the model having a good fit based on Hu and Bentler's (1999) standards of fit indices. 
Table 3 Mean scores of ICLT items measuring characteristics of change leaders in academic institutions

\begin{tabular}{|c|c|c|c|}
\hline Item & Ideal mean & Actual mean & Discrepancy \\
\hline Is lazy and lacks initiative $(r)$ & 5.41 & 5.18 & .23 \\
\hline Is arrogant $(r)$ & 5.36 & 5.08 & .28 \\
\hline Is honest, credible, and respected & 5.34 & 4.90 & .44 \\
\hline Inspires and motivates team members to perform at their best & 5.30 & 4.63 & .67 \\
\hline Leads by example and walks the talk regarding the change & 5.30 & 4.68 & .62 \\
\hline Consults team members and allows them to participate & 5.29 & 4.63 & .66 \\
\hline Is an effective coach and mentor & 5.28 & 4.64 & .65 \\
\hline Maintains a positive outlook throughout the change implementation & 5.28 & 4.88 & .39 \\
\hline Is innovative and creative & 5.26 & 4.73 & .54 \\
\hline Is firm in resolving problems and making decisions & 5.25 & 4.72 & .53 \\
\hline Clearly communicates plans as well as his/her expectations & 5.20 & 4.70 & .50 \\
\hline Shows intelligence and competence to drive the change & 5.19 & 4.74 & .44 \\
\hline Is persuasive; can convince people of the need for change & 5.18 & 4.69 & .50 \\
\hline Is open-minded about the change & 5.17 & 4.76 & .41 \\
\hline Shows trust in people & 5.17 & 4.62 & .55 \\
\hline Remains composed under pressure & 5.17 & 4.65 & .53 \\
\hline Cares for team members and shows consideration & 5.17 & 4.78 & .39 \\
\hline Shows empathy & 5.17 & 4.67 & .49 \\
\hline Is rational and analytical & 5.13 & 4.59 & .54 \\
\hline Adapts to new ways readily and quickly & 5.11 & 4.54 & .56 \\
\hline Drives execution and accountability & 5.09 & 4.70 & .39 \\
\hline Is approachable and always available & 5.08 & 4.57 & .51 \\
\hline Supports team members during the change & 5.07 & 4.78 & .29 \\
\hline Is proactive in anticipating issues and problems & 5.06 & 4.53 & .53 \\
\hline Is bossy and authoritarian $(r)$ & 4.92 & 4.66 & .26 \\
\hline Is too emotional or quickly changes moods $(r)$ & 4.88 & 4.56 & .32 \\
\hline Is disorganized and lacks focus $(r)$ & 4.86 & 4.91 & .05 \\
\hline Lacks long-term thinking $(r)$ & 4.40 & 4.45 & .05 \\
\hline Is passive and has no political will ( $r$ ) & 4.03 & 4.08 & .05 \\
\hline Micromanages people $(r)$ & 3.51 & 3.55 & .04 \\
\hline Total mean & 5.05 & 4.65 & \\
\hline Total SD & .75 & .87 & \\
\hline
\end{tabular}

Table 4 Mean, SDs and Correlations of ICLT, change management, affective, and continuance commitment to change variables

\begin{tabular}{lrrrrr}
\hline Variable & Mean & SD & \multicolumn{2}{l}{ Correlations } & \\
\cline { 3 - 6 } & & & ICLT & Perceived CM & Affective \\
\hline ICLT & .41 & .77 & & & \\
Perceived CM & 4.26 & .90 & $-.44^{* *}$ & & \\
Affective CC & 4.72 & .80 & $-.16^{* *}$ & $.38^{* *}$ & \\
Continuance CC & 3.30 & .99 & $.12^{* *}$ & $-.23^{* *}$ & $-.46^{* *}$ \\
\hline
\end{tabular}

**Correlation is significant at the .01 level (2-tailed)

With the purpose of establishing the value of perceived effective change management as a mediator between ICLT and teacher's affective commitment to change, Table 5 summarizes the test of mediation results.
Results support Hypothesis 1 postulating that implicit change leadership schemas inversely predict perceived effective change management $(\beta=-.44 ; p<.001)$. When the discrepancy between the behaviors of the ideal and the actual leaders is small, the perception of effective change management increases. ICLT accounts for $19 \%$ of the variance in the perceived effectiveness of change management.

As predicted in Hypothesis 2, ICLT also inversely predicted commitment to change $(\beta=-.17 ; p<.001)$. The smaller the discrepancy between ideal and actual leadership behavior, the higher chances teachers will commit to the change.

Furthermore, results support Hypothesis 3 stating that change management mediates the relationship between ICLT and teachers' commitment to change, albeit partially. Perceived effective change management was a significant 


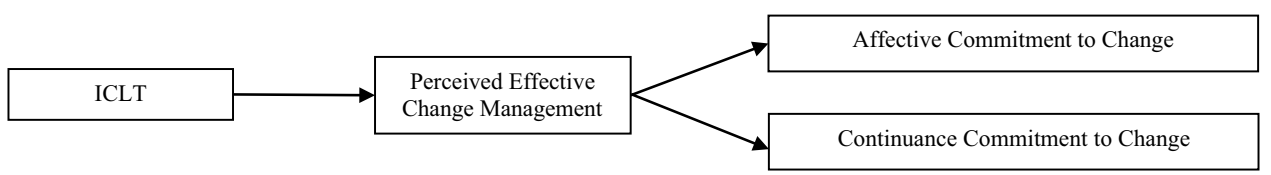

Fig. 3 Modified model of the hypothesize relationship between ICLT, effectiveness of change management, affective, and continuance dimensions of commitment to change in academic institutions

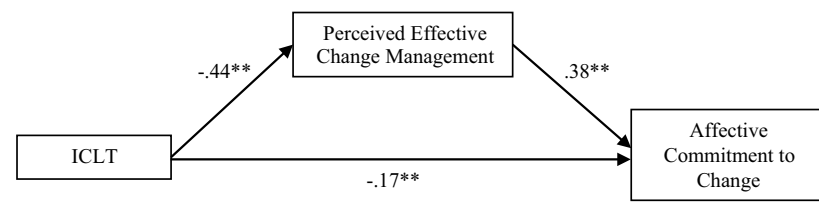

Fig. 4 Emerging model of the interaction between ICLT, change management, and the affective dimension of commitment to change in academic institutions

Table 5 Test of mediation of perceived effective change management between ICLT and affective commitment to change in secondary schools

\begin{tabular}{lcc}
\hline & $\beta$ & $R^{2}$ \\
\hline ICLT $(I V) \rightarrow$ perceived effective change management $(\mathrm{MV}) \rightarrow$ com- \\
mitment to change (DV) & & \\
$\mathrm{IV} \rightarrow \mathrm{DV}$ & -.17 & .03 \\
$\mathrm{IV} \rightarrow \mathrm{MV}$ & -.44 & .19 \\
$\mathrm{IV} \rightarrow \mathrm{MV} \rightarrow \mathrm{DV}$ & .38 & .14 \\
\hline
\end{tabular}

Sobel test $=-8.07, p<.01$

Type of mediation: partial

mediator as it increases the effect of ICLT on commitment to change. This suggests that congruence between the teachers' schema of ideal change leaders and their observations of their actual change leaders, leads to effective change process that, in turn, increases commitment to change.

\section{Discussion}

The findings of this study contribute to a deeper understanding of change leadership in schools in three ways. First, it validates the significance of change leadership schemas of teachers. Second, it demonstrates the relationship of change leadership on perceived effectiveness of change management and commitment to change of teachers. Lastly, it reaffirms the findings in previous studies on the mediating role of change management in schools (Hechanova and Cementina-Olpoc 2013) in the relationship between leadership and teachers' commitment to change.

\section{Implicit leadership schemas in academic institutions}

This study examined change leadership schemas of teachers. However, unlike the five dimensions of change leadership schemas found by Magsaysay and Hechanova (2017) in business organizations, the schemas of teachers clustered into only one dimension. One possible explanation for this is the underlying differences between the two types of organizations. As explained by Hechanova and Cementina-Olpoc (2013), leadership in business institutions tends to be vested in position, whereas academic institutions require a collegial type of leadership. Colley, Hodskinson and Malcolm (as cited in Sosik et al. 2005) suggested that friendship, collaboration, collegiality and shared values are intrinsic rewards in the academe. Thus, leadership may be viewed as a 'rite of passage' where leaders are not necessarily selected based on specific competencies. Hence, although ICLT dimensions were not present in the study, the construct still appears to be relevant in the school setting. In fact, teachers have indicated that they appreciate leaders who are humble, honest, credible, and respected. They also find it ideal when principals motivate and lead, at the same time encourage their participation through coaching and mentoring, while maintaining a positive outlook. These leadership characteristics are indicative of teachers valuing principals as their guide and model for appropriate behaviors during change.

There were also observed differences in the findings of this study and those in business organizations. In the study of Magsaysay and Hechanova (2017), business organizations rated character dimension highest among the five categories of schema. Some items in the character dimension are also seen in the top responses of academic institutions (e.g., is not arrogant or being humble). However, most items highly valued by teachers are competencies in execution (e.g., not lazy and has initiative, inspires, and motivates team members to perform at their best, is an effective coach and mentor), which were rated least in business organizations. These are consistent with what has been termed as servant leadership, which is described as needs-focused and other-oriented and has been associated with academic leaders (Ha et al. 2018).

Another explanation for the leadership schemas is the familial nature of relationships within academic institutions. As Viernes and de Guzman (2005) posited, work relationships in schools take on a family orientation where colleagues are considered parents, brothers, and sisters. For this reason, 
interactions in school settings also entail providing spiritual, emotional, and moral support. In the results of the study, this can be inferred in teachers' expectation of having inspirational and motivational leaders who take on the role of coaches and mentors. Principals are expected to maintain effective support networks during change for teachers to be more confident and secure (Brooks and Sutherland 2014; Leo and Wickenberg 2013). In addition, setting and abiding by targets and deadlines are generally not well-established practice in academic institutions (Bulawa 2012). This may be the reason why execution competencies were emphasized by respondents.

\section{Implicit leadership schemas as a predictor}

Another aim of this study is to explore the predictive nature of change leadership schemas to change management and commitment to change. Results support the predictive value of ICLT to both factors. Teachers' observations vis-à-vis their implicit expectations will affect how they see change is being managed, as well as predict how likely they will commit to the change. This complements findings in literature on the relationship between leadership and commitment to change (Seo et al. 2012). At the same time, Ozdemir et al. (2016) noted that employees find it crucial for school managers to have the required knowledge to promote change. These imply that perception of leaders' behaviors and their attitude have a big impact on employees.

\section{Change management as a mediator}

The results also validate the mediating effect of perceived effective change management. McShane and VonGlinow (2005, p. 419) argued that the success of change efforts is influenced by the ability of leaders to enable organization members to commit to the changes. This study also echoes findings of Hechanova and Cementina-Olpoc (2013), who observed that leadership has a stronger influence on teachers' commitment to change when seen through effective change management processes. Hartkamp et al. (2008) explained that affective commitment to change is primarily affected by the quality of relationships with leaders. As revealed in Brooks and Sutherland's (2014) study on educational leadership, principals effectively facilitate change by establishing meaningful relationships, procuring resources, and providing professional development opportunities for teachers to implement the change.

\section{Limitations and recommendations for research}

Although this study had multiple contributions, it is not without limitations. The responses were gathered from self-reports of teachers, and only during one point in time. Thus, there is a possibility of common method bias. Although this was addressed and determined not to be a concern based on the results of Harman's single factor test (Podsakoff et al. 2003), other sources may also be engaged (e.g., the teachers' supervisors) in providing information on variables that measure behavioral manifestations of the teachers' support for the change.

Another limitation of this study is its inability to control for the stage of change that the different organizations were experiencing. As discussed in change management literature, different stages of change require different strategies of management (Gaubatz and Ensminger 2015; Hannagan 1998). As such, teachers' expectations of academic change leaders may also vary accordingly. A teacher may expect different behaviors from their leader while planning, during implementation, and when evaluating change. Future studies may explore administering the questionnaires at different points in time. Although this study confirmed perceived effective change management as a valuable factor in espousing teachers' commitment to change, looking at other elements of change may provide further knowledge for school leaders to plan for change more effectively. In addition, the effect of teacher characteristics, such as sex and age, on commitment to change may be explored in future studies.

\section{Conclusions and implications}

The findings highlight the change leadership schemas of teachers in academic institutions. It suggests the importance of all implicit change leadership dimensions (strategic and technical, execution, social, character, and resilience) in selecting and developing change leaders in schools. In addition, this study supported and expanded literature on ICLT by confirming the influence of change leadership schemas on perceived effective change management, and establishing that change management mediates the relationship between change leadership schemas and teachers' commitment to change. These suggest the significance of the change management processes being implemented in schools and the need for ample training to provide academic leaders the ability to effectively implement change. For example, results suggest the need to ensure transparency, establish effective communication, 
and practice mapping out responsibilities clearly. Other management processes to consider include strategy, preparation \& readiness, culture, management support, teamwork, technology \& process, and organization structure $\&$ workflow. When recognized as consistent efforts, these initiatives will encourage teachers to develop affective commitment to the changes in the institution.

In summary, this paper offers a wider understanding of implicit change leadership schemas by illustrating its applicability to academic institutions. Results highlight the value of change leadership schemas and change management, in predicting teachers' commitment to change. As such, school management may develop better approaches in getting teachers committed to organizational changes by enabling leadership, selecting and developing change leaders, and ensuring supportive change management processes in their organizations.

Acknowledgements We would like to thank the Ateneo Center for Organization Research and Development (Ateneo CORD) and Ms. Aylin Bello for the assistance in the completion of this study. We also acknowledge the support of the Asian Association of School HRMD Practitioners (AASHPHI) and the Department of Education-National Capital Region.

\section{References}

Ashkenas, R., Siegal, W., \& Spiegel, N. (2013). Mastering organizational complexity: A core competency for 21 st century leaders. Research in Organizational Change and Development, 21, $29-58$.

Brooks, J. S., \& Sutherland, I. E. (2014). Educational leadership in the Philippines: Principals' perspectives on problems and possibilities for change. Planning \& Changing, 45(3/4), 339-355.

Bulawa, P. (2012). Implementation of the Performance Management System (PMS) in senior secondary schools in Botswana: An investigation of senior management team's expected benefits of the PMS. European Journal of Educational Research, 1(4), 321-337.

Epitropaki, O., \& Martin, R. (2005). From ideal to real: A longitudinal study of the role of implicit leadership theories on leader-member exchanges and employee outcomes. Journal of Applied Psychology, 90(4), 659-676. https://doi. org/10.1037/0021-9010.90.4.659.

Fedor, D. B., Caldwell, S., \& Herold, D. M. (2006). The effects of organizational changes on employee commitment: A multilevel investigation. Personnel Psychology, 59, 1-26.

Gaubatz, J., \& Ensminger, D. C. (2015). Secondary school department chairs leading successful change. International Journal of Education Policy \& Leadership, 10(6), 1-21.

Ha, L., Bi, N. C., \& Zhang, F. (2018). Leadership style and success experience of Chinese women academic leaders. China Media Research, 14(1), 1-10.

Hannagan, T. (1998). Management concepts \& practices (2nd ed.). London: Pitman Publishing.

Hartkamp, M., ter Hoeven, C., \& Pieterson, W. (2008). Resolving resistance: The role of commitment to change in public organizations. Conference Papers-International Communication Association (pp. 1-25).
Hechanova, R., \& Cementina-Olpoc, R. (2013). Transformational leadership, change management, and commitment to change: A comparison of academic and business organizations. AsiaPacific Education Researcher, 22(1), 11-19. https://doi. org/10.1007/s40299-012-0019-z.

Hechanova, R., \& Teng-Calleja, M. (2011). Predicting commitment towards organizational change. Journal of Social Transformation, 1(2011), 21-39.

Herscovitch, L., \& Meyer, J. P. (2002). Commitment to organizational change: Extension of a three-component model. Journal of Applied Psychology, 97(3), 474-487. https://doi. org/10.1037/0021-9010.87.3.474.

How DepEd prepares for the K to 12 program [Infographic]. (2015). K-12 Philippines website. Retrieved from http://k12philippines. com/how-deped-prepares-for-the-k-to-12-program-infographic/.

Hu, L., \& Bentler, P. (1999). Cutoff criteria for fit indexes in covariance structure analysis: Conventional criteria versus new alternatives. Structural Equation Modeling, 6(1), 1-55.

Kin, T., Abdull Kareem, O., Wai Bing, K., \& Nordin, M. (2015). Teacher change beliefs: Validating a scale with structural equation modelling. School Leadership and Management, 35(3), 266-299. https://doi.org/10.1080/13632434.2014.962503.

Leo, U. A., \& Wickenberg, P. A. (2013). Professional norms in school leadership. Change efforts in implementation of education for sustainable development. Journal of Educational Change. https://doi.org/10.1007/s10833-013-9207-8.

Magsaysay, J., \& Hechanova, R. (2017). Building an implicit change leadership theory. Leadership and Organizational Development Journal, 38(6), 834-848. https://doi.org/10.1108/ LODJ-05-2016-0114.

McShane, S., \& VonGlinow, M. A. (2005). In search of leader integrity. Organizational behavior: Emerging realities for the workplace revolution (3rd ed., pp. 419-440) New York: McGraw-Hill.

Melville, W., Bartley, A., \& Weinburgh, M. (2012). Change forces: Implementing change in a secondary school for the common good. Canadian Journal of Educational Administration and Policy, 133, 1-26.

Ozdemir, T. Y., Karakose, T., Uygun, H., \& Yirci, R. (2016). Educational employees' perceptions regarding changes in educational organizations. Revista De Cercetare Si Interventie Sociala, 53, 288-303.

Parco-Tropicales, M., \& de Guzman, A. (2014). A structural equation model (SEM) of the impact of transformational, visionary, charismatic and ethical leadership styles on the development of wise leadership among Filipino private secondary school principals. Asia Pacific Education Review, 15(4), 547-559. https:// doi.org/10.1007/s12564-014-9346-5.

Podsakoff, P., Mackenzie, S., Lee, J. Y., \& Podsakoff, N. (2003). Common method biases in behavioral research: A critical review of the literature and recommended remedies. Journal of Applied Psychology, 88(5), 879-903.

Sarvi, J., Munger, F., \& Pillay, H. (2015). Transitions to K-12 education systems: Experiences from five case countries. Manila: Asian Development Bank.

Seo, M., Taylor, M. S., Hill, N. S., Zhang, X., Tesluk, P. E., \& Lorinkova, N. M. (2012). The role of affect and leadership during organizational change. Personnel Psychology, 65(1), 121-165. https://doi.org/10.1111/j.1744-6570.2011.01240.x.

Sosik, J. J., Lee, D., \& Bouquillon, E. (2005). Context and mentoring: Examining formal and informal relationships in high tech firms and K-12 schools. Journal of Leadership and Organizational Studies, 12(2), 94-108.

Tabachnick, B., \& Fidell, L. (2007). Using multivariate statistics (7th ed.). New Jersey: Prentice Hall International. 
Taş, A. (2009). Evaluation of teachers' perceptions related to high school principals' behaviors about change management. Inonu University Journal of The Faculty of Education (INUJFE), 10(2), 1-3.

Viernes, S. M., \& de Guzman, A. B. (2005). Filipino teachers' experiences of supportive relationships with colleagues: A narrative-biographical inquiry. Asia Pacific Education Review, 6(2), 137-142.

Yermack, J., \& Forsyth, D. R. (2016). Students' implicit theories of university professors. Scholarship of Teaching and Learning in Psychology, 2(3), 169-178. https://doi.org/10.1037/st10000067. 